\title{
The Nordic Geodetic Observing System (NGOS)
}

\author{
Markku Poutanen \\ Finnish Geodetic Institute, Geodeetinrinne 2, 02430 Masala, Finland \\ Per Knudsen \\ Danish National Space Center, Juliane Maries Vej 30, 2100 Copenhagen, Denmark \\ Mikael Lilje \\ National Land Survey of Sweden, SE-801 82 Gävle, Sweden \\ Torbjørn Nørbech \\ Norwegian Mapping Authority, 3507 Hønefoss, Norway \\ Hans-Peter Plag \\ University of Nevada, 1664 North Virginia Street, Reno, NV 89557-0042, USA \\ Hans-Georg Scherneck \\ Onsala Space Observatory, SE-439 92 Onsala, Sweden
}

\begin{abstract}
The Nordic Geodetic Observing System (NGOS) integrates fundamental geodetic techniques for the long-term observation of Earth system parameters. The Nordic Geodetic Commission (NKG) established a Task Force with the mission to prepare a document providing the definition and draft for the implementation of the NGOS.

The regional system aligns with international efforts such as the Global Earth Observation System of Systems (GEOSS) and Global Observing Systems and adheres to the Integrated Global Observing Strategy (IGOS). Recent developments in the structure and function of the International Association of Geodesy cumulated in the establishment of the Global Geodetic Observing System, GGOS. NGOS is planned as a regional implementation and densification of the GGOS.

The NGOS is proposed as a system that will serve a wide range of scientific and practical applications. For the Nordic countries, a main focus will be on crustal motion, dynamics of glaciated areas and sea level. NGOS aims to provide geodetic observations for the Nordic area that are of sufficient quantity and quality to serve most of the needs of global Earth observation as well as practical and scientific applications in the region. In particular, NGOS will contribute to the GGOS and other IAG Services; European activities such as EUREF, ECGN, EUVN, and ESEAS; provide the reference frames for the Nordic countries, as well as contribute to the global ones; support scientific projects related to the geodynamics of the Nordic area and provide ground-truth for satellite missions. In this paper we describe the plans and current status of the NGOS.
\end{abstract}

Keywords: geodetic observing system, geodetic observations, reference frames

\section{Introduction}

The three pillars of geodesy according to Bruns as stated in the $19^{\text {th }}$ century are geometrical geodesy (constructing the terrestrial polyhedron), astronomical geodesy (tracing the motion of the polyhedron in inertial space) and gravimetry (derive gravity potential or height differences between the points of the polyhedron). This concept is still valid, although the resolving power of the primary parameters has moved to the parts per billion level, and many more processes can be studied at this level.

The space-based technologies allow us now to determine positions in a globally coherent and highly accurate reference frame. Key variables of the Earth system such as the movements of the tectonic plates, land movement, Earth rotation, changes in the gravity field, and sea level changes are now observable in a globally consistent reference frame. There is an increasing demand for accurate geodetic observations for many scientific and non-scientific applications. However, the accuracy level achieved reveals inconsistencies between the global reference frame and the regional and national frames established for practical use.

The regional system aligns with international efforts such as the Global Observing Systems and adheres to the Integrated Global Observing Strategy (IGOS, see http://www.eohandbock.com/igosp/ and the documents available there). However, Plag (2000) pointed out that none of these observing 
systems includes a geodetic component or is directly connected to the extensive global geodetic observing networks established over the last decade. Thus, until very recently, the fundamental role of geodesy as the backbone for all Earth observation was not formally acknowledged in the frame of global Earth observations.

Over the last five years, the European Commission and the European Space Agency have jointly proposed a programme for Global Monitoring for Environment and Security (GMES). The needs of GMES in terms of observational infrastructure as well as data management and information system can be expected to be a major driver for the development of observation networks and applications over the next decade.

During the last two years, the establishment of the Global Earth Observation System of Systems (GEOSS, see GEO, 2005a, b) has dramatically changed the landscape of global Earth observation. IAG was actively involved in the development of the GEOSS Implementation plan, and the fundamental role of geodesy as the provider of the global reference frame and important observations of the Earth's shape, gravity field and rotation is widely acknowledged (see GEO, 2005b).

The new structure of the International Association of Geodesy (IAG) beyond 2000 defines projects as an entity of coordinated long-term activities (Beutler et al., 2000a, b). At the XXIII General Assembly of the IUGG in Sapporo, Japan, July 2003, the Integrated Global Geodetic Observing System (IGGOS, see Rummel et al., 2001, Beutler et al, 2003; later on GGOS, Global Geodetic Observing System) has been established as such a project.

GGOS will contribute to large international observation and science programs. Large parts of the physical observing network of the GGOS are already in place through the efforts of the national mapping authorities and other institutions involved in operational monitoring. These networks are contributing e.g. to the International Celestial and Terrestrial Reference Frames (ICRF and ITRF).

In parallel and in response to the international developments, geodesists in the Nordic countries have worked towards the definition of an integrated geodetic observing system in the Nordic countries. The Nordic Geodetic Commission (NKG) has recognized the necessity for contributions to global geodetic networks as well as regional homogenisation and standardization and promoted these in the Nordic region. Responding to the international development in Earth observation, since 1998 NKG working groups have discussed the rational and objectives as well as the potential applications of a Nordic Geodetic Observing System (NGOS).

In 2002, the NKG presidium set up a Task Force with the mission to prepare a document providing the definition and draft for the implementation of the NGOS. The authors of this paper were nominated to prepare the plan and the present document. The full document of the NGOS Task Force can be found in the web pages of the NKG, http://www.nkg.fi (Poutanen et al., 2005b, c).

\section{Application of geodetic observations}

A global geodetic observing system provides the infrastructure and observations to determine and maintain an accurate and stable global terrestrial reference frame, and delivers observations of the changes in the geometry and rotation of the solid Earth as well as changes in the Earth's gravity field. In order to detect slow changes in the Earth system, the long-term stability of the reference frame is crucial. The geodetic observations from permanent networks are fundamental for the definition and maintenance of these reference frames.

Gravity measuring satellites CHAMP, GRACE and GOCE will provide us an information on the Earth's gravity field which eventually will enable a precise realization of a global vertical datum but also allows us to monitor the gravity changes.

Changes in the Earth's geometry, gravity field and rotation are caused by mass movements and dynamical processes in the Earth system. Consequently, observations of these quantities provide a means to monitor the dynamics of the Earth system and associated mass movements, such as fluxes in the hydrological cycle including ocean circulation, ground water storage, terrestrial surface flows, sea level changes and ice changes.

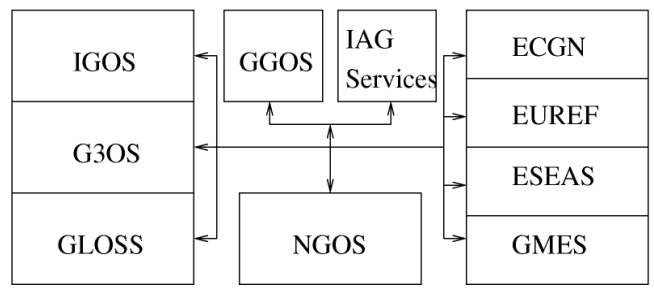

Figure 1. Relations of NGOS to other activities. $(\mathrm{ECGN}=$ European Combined Geodetic Network; ESEAS = European Sea-Level Service; EUREF = Reference frame subcommission for Europe; G3OS = Global Observing Systems; GGOS = Global Geodetic Observing System; GLOSS = Global Sea Level Observing System; GMES = Global Monitoring for Environment and Security; IAG = International Association of Geodesy; IGOS = Integrated Global Observing Strategy; NGOS = Nordic Geodetic Observing System) 


\subsection{Positioning, changes in positions, and displacements}

In maintaining the reference frames and monitoring the Earth system, GPS augmented with the products of the IGS (International GNSS Service) has served both as the primary measuring device as well as a tool to position sensors with unprecedented accuracy. Ten years of experience have shown that accuracies are of the order of better than $1 \mathrm{~cm}$ in daily or sub-daily positions and better than $1 \mathrm{~mm} / \mathrm{yr}$ in secular stability.

Today, the International Terrestrial Reference Frame (ITRF) is the most accurate global frame available. On the global scale, monitoring the surface kinematics through the ITRF network and particularly its densest component, the IGS network, has contributed significantly to improvements of the global plate motion model. Additional improvements can be expected mainly through better coverage of the Earth surface with continuous GPS (CGPS) sites and also other spacegeodetic stations. Accuracy requirements are of the order of $1 \mathrm{~mm} / \mathrm{yr}$ or better.

For the vertical velocities no general global model exists. However, for postglacial rebound as one of the major causes in Northern Europe and Canada, geophysical models provide predictions with accuracy on the 2-3 mm/yr level. Most of the Fennoscandian uplift, however, can be reconstructed better than $1 \mathrm{~mm} / \mathrm{yr}$ due to repeated precise levelling since last 100 years, and current CGPS networks.

In the BIFROST project (see e.g. Scherneck et al., 1998, Milne et al., 2001, Johansson et al., 2002), both the vertical and horizontal post-glacial rebound signal could be detected in long ( $>$ five years) CGPS time series of a regional network. Significant differences of model predictions due to differences in the Earth and ice models used to compute the present-day kinematics are of the order of $1 \mathrm{~mm} / \mathrm{yr}$ and $<0.5 \mathrm{~mm} / \mathrm{yr}$ in the vertical and horizontal components, respectively.

On seasonal and subseasonal time scales, the changes in the shape of the Earth as observed by the global and regional geodetic networks have been used to extract the signal due to surface loading (e.g. van Dam and Herring (1994), van Dam et al. (1994), and van Dam et al. (2001)). In order to contribute to a validation of different loading models, this sets a requirement for the precision of daily coordinates (e.g. Poutanen et al., 2005a).

Increasingly, GNSS is used to monitor the motion and stability of large infrastructure such as oil platforms, reservoir dams and bridges. User requirements for monitoring of such infrastructure are of the order of less than $1 \mathrm{~cm}$ for sub-daily to daily positions available with a latency of a few days, 2-3 $\mathrm{mm}$ on monthly to seasonal time scales, and $1 \mathrm{~mm} / \mathrm{yr}$ for long-term stability (Plag, 2004).

A key limitation for monitoring infrastructure at points far away from a stable reference point is the temporal stability of the global reference frame. Many applications require an accuracy of $5 \mathrm{~cm}$ over a time span of up to 50 years, which is equivalent to a long-term stability of $1 \mathrm{~mm} / \mathrm{yr}$.

\subsection{Earth rotation}

The NGOS as a regional effort offers a high-quality capability contributing to global monitoring of earth rotation, primarily with VLBI. The aim is submillimetre stability and calls for corresponding stability monitoring. The methods are, besides collocation of techniques, regional footprinting in e.g. GPS networks. This is an essential requirement in order to achieve the necessary consistency of reference frames.

Earth rotation monitoring is carried out in sparse networks. The stability of the participating stations plays a key role. Future demands of site stability will probably range below $0.1 \mathrm{~mm}$ (horizontal standard deviation). Emphasis is therefore given to a few well-collocated stations that can be followed up with local footprint studies under long time. The three stations $\mathrm{Ny}$ Ålesund, Metsähovi and Onsala continue to be important international resources. Collocated GNSS stations will help to improve the short-term resolution of EOP time series, but VLBI is the only technique available that is capable to link the terrestrial reference frame to the celestial frame on a routineous basis.

Earth orientation parameters are key parameters for global reference frames. Need for continuous monitoring and rapid solutions is likely to increase somewhat. Continuous monitoring is already implemented on a global scale; however, increasing need for higher accuracy will probably call for a somewhat larger number of stations in simultaneous networks.

Climate-related processes, especially the El Niño phenomenon in the Pacific, leave discernible fingerprints in earth rotation variations. This area has high potential for further discoveries. With the increasing length of observational time series and settling of uncertainties at still better levels more subtle changes in the atmospheric-oceanic angular momentum budget and effects of atmospheric and oceanic torques on nutation and polar motion can probably be observed. 


\subsection{Gravity and its changes}

National gravity networks have been maintained with relative gravimetric measurements. There have been only a limited number of absolute gravity points. In recent years, possibilities to make absolute measurements have been improved. We are moving toward the situation where the primary reference network is maintained by absolute measurements and the sites are common with those of other techniques, e.g. permanent GPS stations.

Measuring the secular change of gravity in a gravimetric network of permanent stations over long periods of time affords a unique method to monitor large-scale mass movements. Of particular interest in our area is the phenomenon of postglacial rebound. Combining gravity change with surface displacement promises to help discern ice load related effects from earth structure. In order to resolve models of mass redistribution in glacial isostatic rebound models, gravity change needs to be determined at 1 to $2 \mathrm{~nm} / \mathrm{s}^{2} / \mathrm{yr}$ reproducability.

Measurements with modern instruments like superconducting gravimeters and ancillary monitoring of environmental parameters like ground water, rain, snow, lake and sea levels constitute an ongoing research effort, partly in its own right and partly in direct support of the absolute gravity network. Consistency is required at the $0.1 \mathrm{~nm} / \mathrm{s}^{2}$ level, which still is a challenge at seasonal to inter-annual periods.

Superconducting gravimeters are very sensitive instruments to monitor gravity changes. However, they have no absolute scale of their own, and due to (unknown) drift, need to control with regular absolute measurements at the same site. In the Nordic area, one needs to ensure that the existing superconducting gravimeter (currently only one) has an adequate good tie to the frame measured by absolute gravimeters.

Satellite gravity missions such as the ongoing Gravity Recovery and Climate Experiment (GRACE) and the upcoming Gravity Field and Steady-State Ocean Circulation Mission GOCE, maps the Earth gravity field with high accuracy almost globally. For calibration and validation of the data a-priori information about the gravity field is needed at least in some regions. In those regions, information about the spatial characteristics of the gravity field can be compiled using terrestrial measurements combined with airborne and shipborne surveys. Absolute gravity is essential as fundamental information to define the level as well as to calibrate and validate the gravity relative gravity data.

\subsection{Geoid}

The geoid is an equipotential surface associated with the Earth gravity field. The geoid as an equilibrium surface defines the reference for physical processes such as mass movements. With the increased use of the Global Navigation Satellite System (GNSS) in height determination, accurate information about the geoid has become essential. Satellite positioning is carried out with the respect to a global reference frame and the height is referring to the ellipsoid. To convert ellipsoidal heights to orthometric heights a geoid model is needed.

In ocean science the differences between the ocean surface and the geoid (called the dynamic topography) is important for studies of the dynamics of the ocean, its currents and heat transport. An accurate geoid is required to study the changes in the currents and the heat transport and their role in climate.

On the surface of the solid earth the movements of water and ice naturally depend on the gravity. In the Earth's interior movements of mass are caused by the variations in the gravity potential field combined with the visco-elastic properties of the earth materials. The postglacial rebound in the Nordic region, where the crust in the central part of the region moves up by $1 \mathrm{~cm}$ per year, is such a phenomenon.

As surveying on land by levelling etc. is carried out with respect to the geoid, positioning and navigation by gyros in Inertial Navigation Systems (INS) refer to the geoid, or more correctly to the gravimetric equipotential surface, the geoid defines.

Use of data of the gravity satellites CHAMP, GRACE and GOCE will eventually produce a global geoid model, the accuracy of which is better than couple of centimetres. This enables creation of vertical datums anywhere which are globally consistent within the geoid model accuracy.

\subsection{Combination of observations}

Space-based segments can remotely observe several key quantities (global ocean surface, ice surface, gravity field at long- and medium-range spherical harmonic degree), while ground-based observations are sensitive to the situation at a very local scale. In the case of a few global quantities, local observations will hardly become obsolete.

GNSS is well suited for measuring the positions of single points in a global reference system. To obtain high accuracies (better than one centimetre) observations need to be acquired continuously on a 
permanent basis. Other space techniques, especially VLBI and SLR, give positions with a higher accuracy.

Classical techniques such as trilateration and levelling can be used for measuring precise relative positions, which after repeated measurements can give local displacements and deformations. Precise levelling is used to determine accurate changes in height to recover local land uplift and subsidence. Land uplift and subsidence relative to mean sea level may be measured using tide gauges. The three techniques, however, measure vertical displacements in three different systems, i.e. relative to the ellipsoid, relative to the geoid, and relative to the mean sea level.

The Earth's rotation is studied using coordinate time series from space techniques as VLBI, SLR and GNSS. Accurate gravity variations from superconducting gravimeters are also used. The determination of earth rotation parameters needs a global coverage of stations.

The determination of the gravity field including the geoid is based on measurements of the accelerations obtained by absolute and spring gravimeters. Spring gravimeters are used for the spatial densification of the gravity network. To study the details of the dynamics of the earth the gravity needs to be measured by superconducting gravimeters.

Glacial isostatic adjustment (GIA) is an illustrative example for a geodynamic problem where coordinated multi-component geodetic observations are essential. The dynamics of the GIA problem is constituted by a planet that has a specific rheology, guiding the response to surface loading.

Today we are beginning to retrieve fully 3-D surface motion at $0.1(0.05) \mathrm{mm} / \mathrm{yr}$ resolution, sea level change below $0.2 \mathrm{~mm} / \mathrm{yr}$, while gravity changes are monitored at a $\mu \mathrm{Gal} / \mathrm{yr}$ level with absolute or relative gravimeters. For mitigating this shortcoming the Nordic absolute gravimetry plan has been launched and several institutes have already increased their level of activity.

The major obstacle for data combinations across all time scales is that the components of the systems have different sampling schemes. For a foreseeable future it is unrealistic to expect permanent absolute gravimeter installations on much tighter than annual campaign schemes. To overcome the drawback the preferred method would be to start and install recording gravimeters (remotely controlled, emphasis on low instrumental drift) at some of the absolute gravity sites.

A well-established, accurate and stable reference is essential for the determination of the changes described above. The realisation and maintenance of the terrestrial reference frame is carried out by means of a global or regional cluster of fiducial points with precise positions relative to some external reference associated with them. The reference frame for gravity is established and maintained using a global or regional cluster of absolute gravity measurements combined with relative measurements.

\section{Components of the Nordic Geodetic Observing System}

NGOS aims to provide geodetic observations for the Nordic area that are of sufficient quantity and quality to serve most of the needs of global Earth observation as well as practical and scientific applications in the region. Taking into account the specific phenomena of the region, NGOS will have a particular focus on geodynamics. Particular focus will be the long-term stability in the observing system, homogeneity in time, and a sufficient capability to perform its tasks also in the future.

The geographic extent of NGOS is currently defined as the Nordic countries, including Greenland and Svalbard (Fig. 2). It is recommended that the geographical region is extended to include also the area of Baltic States. This covers the area of the ice-covered part of the Northern Europe during the last ice age, and therefore the common geophysical interest.

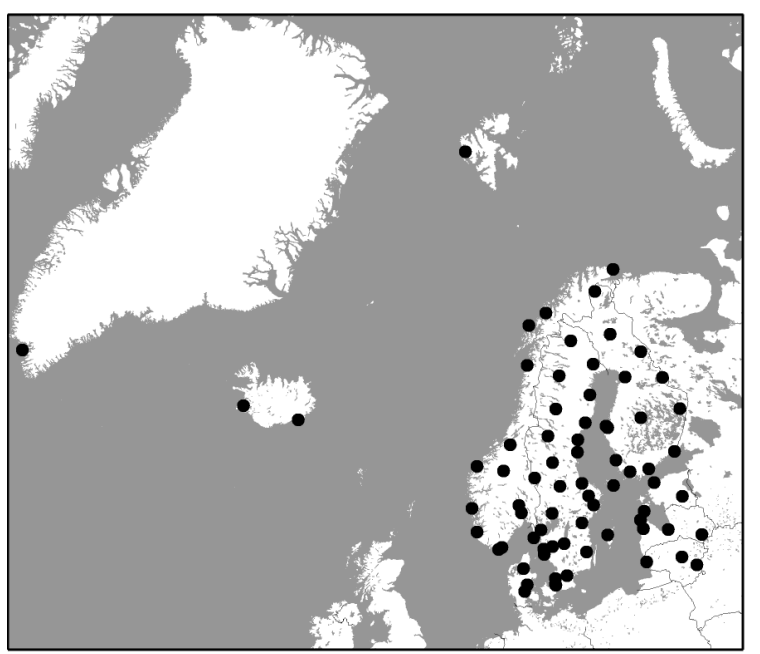

Figure 2. The geographical area covered by the NGOS and proposed NGOS stations. 
Table 1. Summary of techniques considered in NGOS.

\begin{tabular}{|l|l|l|l|}
\hline Technique & Objective & Accuracy & Component(s) \\
\hline VLBI & $\begin{array}{l}\text { Point positioning relative to } \\
\text { space }\end{array}$ & $\begin{array}{l}0.001 \mathrm{ppb} \\
0.1 \mathrm{mas}\end{array}$ & $\begin{array}{l}\text { Surface displacement; Earth rotation; } \\
\text { Reference frame }\end{array}$ \\
\hline SLR & $\begin{array}{l}\text { Point positioning relative to } \\
\text { many satellites }\end{array}$ & $\begin{array}{l}<1 \mathrm{~cm} \text { (range) } \\
1-2 \mathrm{~cm}\end{array}$ & $\begin{array}{l}\text { Surface displacement; Earth rotation; } \\
\text { Reference frame }\end{array}$ \\
\hline GNSS & $\begin{array}{l}\text { Point positioning relative to a } \\
\text { satellite system }\end{array}$ & $\begin{array}{l}\left.\mathrm{E}: 1-2 \mathrm{~cm}{ }^{*}\right) \\
\mathrm{C}: 1-2 \mathrm{~mm}\end{array}$ & $\begin{array}{l}\text { Surface displacement; } \\
\text { Reference frame }\end{array}$ \\
\hline DORIS & $\begin{array}{l}\text { Point positioning relative to } \\
\text { satellites }\end{array}$ & $1-5 \mathrm{~cm}$ & $\begin{array}{l}\text { Surface displacement; } \\
\text { Reference frame }\end{array}$ \\
\hline Levelling & $\begin{array}{l}\text { Height differences of points } \\
\text { relative to the geoid }\end{array}$ & $<1 \mathrm{~mm} / \mathrm{km}{ }^{1 / 2}$ & $\begin{array}{l}\text { Surface displacement; } \\
\text { Reference frame }\end{array}$ \\
\hline Tide gauges & $\begin{array}{l}\text { Height of points relative to sea } \\
\text { level }\end{array}$ & $\begin{array}{l}\mathrm{E}: 10 \mathrm{~cm} \\
\mathrm{C}: 1 \mathrm{~cm}\end{array}$ & $\begin{array}{l}\text { Surface displacement; } \\
\text { Reference frame }\end{array}$ \\
\hline Absolute gravimeters & $\begin{array}{l}\text { Absolute gravimetric } \\
\text { accelerations }\end{array}$ & $\begin{array}{l}\text { Surface displacement; Earth rotation; } \\
\text { Gravity; Reference frame }\end{array}$ \\
\hline $\begin{array}{l}\text { Superconducting } \\
\text { gravimeters }\end{array}$ & $\begin{array}{l}\text { Relative gravimetric } \\
\text { accelerations }\end{array}$ & $\begin{array}{l}0.1 \mu \mathrm{Gal} \\
(<1 \mathrm{nGal} \mathrm{periods})\end{array}$ & $\begin{array}{l}\text { Surface displacement; Earth rotation; } \\
\text { Gravity; Reference frame }\end{array}$ \\
\hline Spring gravimeters & $\begin{array}{l}\text { Relative gravimetric } \\
\text { accelerations }\end{array}$ & $\begin{array}{l}\text { Gravity; } \\
\text { Reference frame }\end{array}$ \\
\hline${ }^{*}$ E means episodical and C continuous measurements & $2-3 \mu \mathrm{Gal}$ & \\
\hline
\end{tabular}

Only the ground components of the geodetic observation techniques and infrastructures are considered in NGOS. Densifications, e.g. in special target areas such as glaciers, tectonically active structures, or near tide gauges, can be accomplished using remote sensing techniques, such as space and airborne radar and laser systems. Sea level can be monitored using satellite altimetry. The large scales of the gravity field and its changes are studied using observations of the motions of satellites by SLR and GPS or by dedicated gravity satellite missions.

NGOS is planned to be a regional implementation of GGOS. Hereby, NGOS is related to the international geodetic cooperation work in the IAG and its associated services. Furthermore, the activities should be coordinated with other international services outside IAG such as PSMSL, and with some European services such as ESEAS.

Concerning spatial variations of gravity and its temporal changes, we propose concentration on the use of modern, absolute gravimeters as expressed in NGOS/Absolute Gravimetry plan (Scherneck et al., 2002) and "Draft plan for absolute gravity campaigns in the Fennoscandian land uplift area" by Mäkinen (2003). The absolute gravity measurements in the Nordic area is made as a cooperation of Danish National Space Center, The Finnish Geodetic Institute, Norwegian Mapping Authority, National Land Survey of Sweden, Onsala Space Observatory (Sweden), Norwegian University of Life Sciences in Aas, University of Hannover (Germany), and Federal Agency for Cartography and Geodesy (BKG, Germany).

We also emphasize the importance of geoid determination. By nature, it is not limited to the
NGOS stations or NGOS plan. In the future, the new gravity satellite missions, especially GRACE and GOCE will give their contribution also to the Nordic geoid models.

\section{Current situation in the Nordic area}

NKG has tried to act as a platform for sharing the knowledge concerning construction of various geodetic networks and in co-operation of geodetic campaigns. However, at the end it has always been the responsibility of an individual country to implement the work in practice. The Nordic countries have historically been building up their geodetic networks quite independently. There has been only a limited amount of co-operation between the countries or techniques.

In each country there are networks of permanent GNSS stations that partly are operated by the national geodetic authorities. The co-ordination concerning e.g. location, construction, facilities and products was not optimal when the stations were built. This means e.g. that the stations have different monumentations, have different types of equipment, produce slightly different products and possibly are not optimally spread over the Nordic Area. However, the basic observables are the same at all stations, thus allowing e.g. the common Nordic computation of the EPN block, or the collaboration in the projects like BIFROST.

GNSS data of some Nordic stations are used in IGS, but a more wide selection of Nordic GNSS stations belong to the EPN, the European Permanent GPS Network, coordinated by EUREF. 


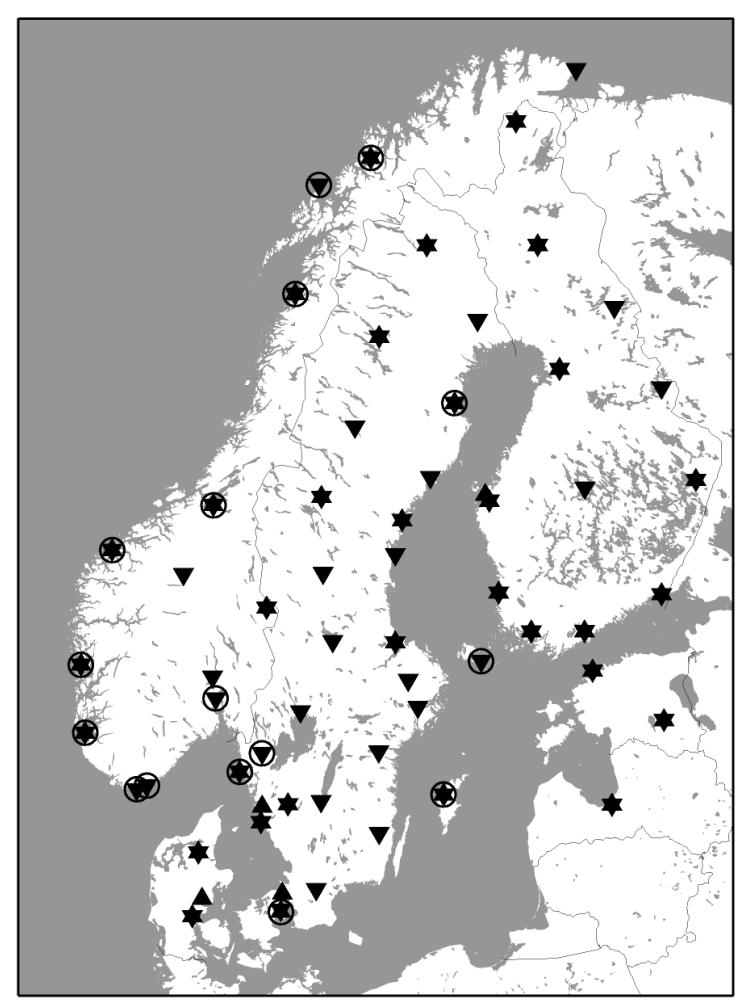

Figure 3. NGOS plan. Absolute gravity points (triangles), Nordic permanent GPS network (upside down triangles) and tide gauges (circles). All absolute gravity points are occupied with a GNSS instrument.

The Nordic countries have adopted national ETRS89-realisations as their national reference systems. NKG is responsible for one of the EPN analysis centres and the responsible organisation is currently the National Land Survey of Sweden. NKG has urged the countries for Nordic cooperation concerning the Nordic height systems.

The joint Nordic adjustment of the levelling networks is headed towards the common vertical datum in the area. NGOS is in line with these initiatives towards Nordic co-operation concerning the national geodetic networks and geodetic stations.

The Finnish Geodetic Institute has been active in absolute gravimetry and has been performing measurements on stations over the Nordic Area for many years. Groups from USA and Germany have also made absolute gravity measurements in the Nordic Area.

The current NGOS AG plan clearly demonstrates the current co-operation in this field. Since 2003, also the Norwegian University of Life Sciences in Aas has an absolute gravimeter which is a substantial increase in the resources. Most of the measurements in Finland and Sweden have been performed at stations with other geodetic techniques, such as permanent GNSS stations and/or tide gauges.

There is a superconducting gravimeter at Metsähovi and Ny-Ålesund. These two stations and additionally Onsala, are also equipped with a geodetic VLBI. Metsähovi has additionally collocated other two space geodetic equipment, namely the SLR and DORIS. Since 1978 Metsähovi has participated the SLR programmes, and is currently the Northernmost SLR station. Stations in geodetic VLBI and SLR contribute to the work of IVS and ILRS which are the IAG services.

Products of the NGOS, data access and archives are to be defined. Geodetic data are spread between the various countries and organisations and are also in various formats. Very little has been done in standardisation of data archives as well as assure the access to data. Different policies in the countries concerning accessibility to data due to pricing policies have complicated this issue.

The characteristics of the NGOS, and NKG behind it, do not imply a common data archive covering all data and products of the NGOS. The role of NGOS data policy should be co-operative, utilising current infrastructure also in data policy and archiving. There already exist working examples of products and data archiving, including the Nordic permanent GPS network, levelling data bank and gravity data. At least in the first step, a NGOS database is needed to list the existing data, how to access to it, and possibly some auxiliary information concerning the use of data and products. It is responsibility of individual institutions to maintain the databases, possibly making a common agreement on data exchange and use, and also the data delivering policy is a national decision.

\section{Conclusion}

We have described the general principles of the NGOS. The final selection of the sites depends on the resources available. We will begin with the sites proposed for the ECGN, added with the sites for absolute gravimetry. One should emphasize the multi-technique approach, and put the priority according to that. During the discussions to be done in the near future we are able to fix the core set of the NGOS stations. The work of the Task Force will continue, because the Presidium of the NKG gave a new task to find out the existing infrastructures and data archives, prepare a status report and recommendations for the practical implementation of the NGOS. We also propose that the work on the 
NGOS on the practical level will be continued in the NKG Geodynamics Working Group.

\section{Acknowledgements}

The NGOS report is a combined effort of a large number of people. In addition to the authors of this paper, many other people have contributed the work, including R. Forsberg, B.R. Pettersen, D. Solheim, J. Mäkinen, M. Vermeer and several other Nordic colleagues not mentioned here. We like to express our sincere thanks to those who have helped us to prepare the NGOS document.

\section{References}

Beutler, G., Drewes, H., and Rummel, R., 2000a. Reflections on a new structure for IAG beyond 2000-conclusions from the IAG Section II Symposium in Munich, in Schwarz, K.P. (ed.): Geodesy Beyond 2000 - The Challenges of the First Decade, pp. 430-437, IAGSymposia 121, Springer.

Beutler, G., Drewes, H., Reigber, Ch., and Rummel, R., 2000 b. Space techniques and their coordination within IAG and in future, in R. Rummel, H. Drewes, W. Bosch, H. Hornik (eds.): Towards an Integrated Global Geodetic Observing System (IGGOS), pp. 22-32, IAG-Symposia 120, Springer.

Beutler G., Drewes H., Reigber C., Rummel, R. (2003): Proposal to establish the Integrated Global Geodetic Observing System (IGGOS) as IAG's First Project. http://www.gfy.ku.dk/ iag/iggos prop june 03.htm.

GEO, 2005a. The Global Earth Observing System of Systems (GEOSS) - 10-Year Implementation Plan. ESA Publication Division, ESTEC, Noordwijk, The Netherlands. Available at http://earthobservations.org/.

GEO, 2005b. Global Earth Observing System of Systems GEOSS - 10-Year Implementation Plan Reference Document. ESA Publication Division, Noordwijk, The Netherlands. No. GEO 1000R/ESA SP 1284, February 2005. Available at http://earthobservations.org/.

Johansson, J. M., Davis, J. L., Scherneck, H.-G., Milne, G. A., Vermeer, M., Mitrovica, J. X., Bennett, R. A., Jonsson, B., Elgered, G., Eløsegui, P., Koivula, H., Poutanen, M., Rönnäng, B. O. and Shapiro, I. I., 2002: Continuous GPS measurements of postglacial adjustment in Fennoscandia 1. Geodetic results, J. Geophys. Res., 107, DOI 10.1029/2001JB000400.

Mäkinen, J., 2003. Draft plan for absolute gravity campaigns in the Fennoscandian land uplift area. Meeting of the NKG Working Group of Geodynamics, Copenhagen, April 29, 2003, 11 p. Available at http://www.oso.chalmers.se/ hgs/NKGWG/Docs/AbsGravCamps03_draft_J M.pdf

Milne, G. A., Davis, J. L., Mitrovica, J. X., Scherneck, H.-G., Johansson, J. M., Vermeer, M., Koivula, H., 2001: Spacegeodetic constraints on glacial isostatic adjustment in Fennoscandia. Science, 291, 2381-2385.
Plag, H.-P., 2000. Integration of geodetic techniques into a global Earth monitoring systems and its implication for Earth system sciences, in R. Rummel, H. Drewes, W. Bosch, H. Hornik (eds.): Towards an Integrated Global Geodetic Observing System (IGGOS), pp. 84-90, IAG Symposia 120, Springer.

Plag, H.-P., 2002.: European Sea Level Service (ESEAS): Status and Plans, in Poutanen, M. and Suurmäki, H. (eds.): Proceedings of the $14^{\text {th }}$ General Meeting of the Nordic Geodetic Commission, Espoo, Finland, 1-5 October 2002, pp 80-88, Finnish Geodetic Institute.

Plag, H.-P., 2004: The IGGOS as the backbone for global observing and local monitoring: a user driven perspective. In Rummel, R., Drewes, H., Bosch, W. and Hornik, H. (eds.): International Association of Geodesy Symposia, Springer, Berlin, in press.

Poutanen M., J. Jokela, M. Ollikainen, H. Koivula, M. Bilker, H. Virtanen, 2005a: Scale variation of GPS time series. In F. Sansò (Ed.) A Window on the Future of Geodesy. IAG General Assembly in Sapporo, Japan 2003. pp. 15-12. IAG Symposia 128, Springer Verlag.

Poutanen M., P. Knudsen, M. Lilje, T. Nørbech, H.- P. Plag, H.-G. Scherneck, 2005b. NGOS. Report of the Nordic Geodetic Commission Task Force. http://www.nkg.fi /nggos.html. 30 pages.

Poutanen M., P. Knudsen, M. Lilje, T. Nørbech, H.- P. Plag, H.-G. Scherneck, 2005c. NGOS - The Nordic Geodetic Observing System. Accepted for the Nordic Journal of Surveying and Real Estate Research. 20 pages.

Rummel, R., Drewes, H., and Beutler, G., 2001. Integrated Global Geodetic Observing System (IGGOS): A candidate IAG project. In Vistas for Geodesy in the New Millennium: IAG 2001 Scientific Assembly, Budapest, Hungary, September 2-7, 2001 (Ed. J. Adam, K.-P. Schwarz). pp. 609-614. IAG Symposia 125. Springer.

Scherneck, H.-G., Johansson, J. M., Mitrovica, J. M., Davis, J. L., 1998: The BIFROST project: GPS determined 3-D displacements in $\mathrm{F}$ ennoscandia from 800 days of continous observations in the SWEPOS network. Tectonophysics, 294, 305-321.

Scherneck, H.-G., Vermeer, M., Forsberg, R., Schmidt, K.E., Mäkinen, J., Ollikainen, M., Poutanen, M., Ruotsalainen, H., Virtanen, H., Völksen, Ch., Plag, H.-P., Lidberg, M., and Olsson, A., 2003. The Nordic Geodetic and Geodynamic Observing System (NGGOS): An NKG plan for the contribution from an absolute gravimetry network (NGGOS/AG), http://www.oso.chalmers.se/simhgs /NKGWG/Docs/Abs Grav Plan.pdf

van Dam, T. M. and Herring, T. A., 1994: Detection of atmospheric pressure loading using very long baseline interferometry measurements. J. Geophys. Res., 99, 45054517.

van Dam, T. M., Blewitt, G. and Heflin, M. B., 1994: Atmospheric pressure loading effects on Global Positioning System coordinate determinations. J. Geophys. Res., 99, 23939-23950.

van Dam, T. M., Wahr, J., Milly, P. C. D., Shmakin, A. B., Blewitt, G., Lavalee, D. and Larson, K. M., 2001: Crustal displacements due to continental water loading, Geophys. Res. Let., 28, 651-654. 